\title{
Discussion: Analysis of a composite bowstring truss with
}

\section{tension stiffening}

\section{R. P. Johnson}

D. Collings, Robert Benaim \& Associates, London, U.K.

Professor Johnson's paper on the methods of analysis of tension stiffened composite sections was interesting. In looking at the tie slab interaction on a wide arch bridge recently the force in the slab at mid-span was estimated as 30 to $50 \%$ depending on the concrete stiffness assumed. Forsberg ${ }^{1}$ outlined some calculations of the effective stiffness on the Oresund approach bridges based on a cracked concrete modulus of 25\% of the uncracked concrete. Professor Johnson does not detail any analysis based on elastic finite element plates (with reduced modulus) in the paper. I would be interested in his views on this, particularly as this is a relatively simple method to use in the design office.

\section{REFERENCES}

1. FoRSBERG T. The Øresund approach bridges. Composite Bridges, State of the Art in Technology and Analysis. Proceedings of the 3rd International Meeting, Madrid, 2001. Colegio de Ingenieros de Caminos, Canales y Puertos, Madrid, 2001, pp. 348-359.

\section{Author's reply}

In the work to which David Collings refers, Torben Forsberg was able to deduce the '25\%' ratio by matching the extension of a concrete beam to that of much heavier steelwork, to which its ends were attached.
Analysis for a wide concrete deck of a tied-arch bridge is more complex, because of the continuous variation of both in-plane shear and longitudinal tension along the length of the deck slab. Near a support, any cracking is mainly due to in-plane shear, with gradual transition to cracks from global tension in the low-shear situation at mid-span.

The appropriate value for a 'cracked concrete modulus' in a finite element analysis would vary along the span. It seems unlikely that any single value could reliably be used, although two values (cracked and uncracked) can provide upper and lower bounds.

The reported work on Newark could lead to a set of values for use in a finite element analysis of that deck. These would depend on the local intensities of both shear and tension, and might not be appropriate for another deck. For example, its span/width ratio might be different, or the in-plane effects might be reduced by the use of a different casting sequence, or of precast deck slabs.

Use of a single concrete modulus for a deck analysis at Newark would have left the problem: 'how should its results be checked?'. 